As THE Council for Mutual Assistance (Comecon) countries considered the end of their 1971-75 Five-year Plans and formulated their plans for the coming five years, a whole series of meetings, conferences and discussions were held of the Standing Comecon Commissions. Plans have been put forward on such diverse matters as the unification of standards for industrial production, the approval of new drugs to be used in the treatment of malignant tumours, the division of labour between the participating countries in the manufacture of electronic components, and specialisation and cooperation in the manufacture of instruments for the artificial insemination of cattle.

For the first time, the new plans will include the construction of joint industrial projects by a number of member countries. And the non-European members of Comecon are not forgotten. Within the framework of the exising scheme for the integration of information systems, Czechoslovakia and Hungary are to provide information systems for Cuba, and the Soviet Union will provide Cuba and Mongolia with industrial, agricultural, and transport equipment in return for basic exports and raw materials.

- The new Polish five-year plan, as laid down by the Seventh Congress of the Polish United Workers' Party which met in Warsaw from December 8-12, envisages a considerable expansion of investment in science. This is despite the fact that the growth of the Polish economy in the five years of the Gierek regime has been facilitated by foreign borrowings which, in bringing demands for interest payments, will make higher prices and food shortages likely over the next five years.

\section{Comecon diary}

from Vera Rich, London

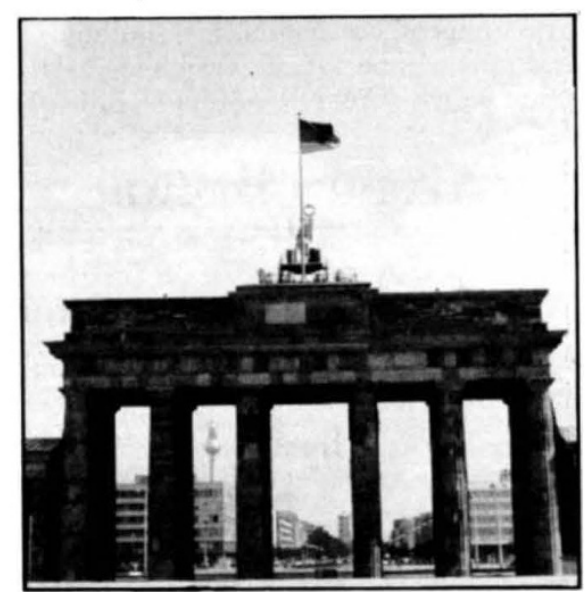

Expenditure on both science and technology is put at 200,000 million zloty, after 115,000 million in the previous five years. Special emphasis is to be placed on research into the more efficient use of fuels, raw materials and water resources, improving the technology of the coal and copper industries, the introduction of aluminium production from native ores and the production of new materials for the electronics industry. The application of science to agriculture, public and occupational health and child care are also mentioned.

According to Sylwester Kaliski, the Minister of Science, Higher Education and Technology, the plans will be im- plemented through a new scheme which, with cooperation between scientists and administrators, will lay the foundation of a "strategy for scientific research and technical advance, a plan composed of government programmes, departmental problems and basic research". This, he said, would unify the whole activity of research and its practical implementations in Poland.

The Polish Academy of Sciences is to play an important role in the research part of this programme, and it is introduced also to involve the universities.

- In the German Democratic Republic's economic plan for 1976, which (if successful) will result in a $5.3 \%$ increase in the national income, a $6 \%$ increase in the production of industrial goods and an improvement in labour productivity of $5.5 \%$, the plan for science and technology envisages more than 160 specific tasks to be fulfilled on time and to a high standard. The "tasks" cover a wide range of applied science, from improved fuel economy in power stations to rationalisation of the washing-powder industry.

The attainment, or otherwise, of the proposed targets may itself be somewhat difficult to evaluate, however. According to the East Berlin Central Statistics Board, a number of enterprises in the GDR have been "interpreting in their own special way" their economic results for 1975 , so that in many cases the figures submitted make the drawing of any sound economic conclusions problematic. The board urges exact calculation, rather than "interpretation", of the figures.

\section{Indian states attack population growth}

\section{from Our Correspondent, Jullundur}

AFTer more than two decades and the expenditure of thousands of millions of rupees, India's family planning programme has achieved only limited success. But Draconian measures proposed by two state governments may well change all that through a revamped and much more severe stick-and-carrot policy to cncourage sterilisation.

Taken up officially in 1952, the Indian birth control programme started off modestly, but only received its first big push after the publication of the 1961 census data, which showed a higher-than-expected rate of population growth. The programme has nevertheless made only slow progress. According to official figures, the present birth and death rates are 36.6 and 16.9 per thousand respectively. Due to improvement in health services, the death rate has fallen and is expected to go down even further. But the slow decline of the birth rate can be attributed to a number of factors. Paucity of funds, inadequate communications and lack of official enthusiasm at lower levels have proved obstructive; but poverty, malnutrition, ignorance, superstition and illiteracy are the more formidable hurdles. There have been suggestions that new families be allowed to have no more than two children. But so far the government has steered clear of introducing compulsion into the programme, even though the population increases each year by an amount equivalent to the population of the whole of Australia.

The state governments of Haryana and Punjab, however, have decided on steps which could spell the beginning of a new trend. The Haryana government has announced a series of measures to promote smaller, twochildren families by means of incentives and disincentives. The state has set itself a target of reducing its net rate of population growth to zero before 1985 .

The incentives include cash prizes worth $100,000,75,000$ and 50,000 rupees, which will be awarded each year to three districts in the state which capture top spots in family planning performance over and above their allotted targets. Factories in the state, where all 'eligible' workers accept sterilisations after two children, will qualify for benefits from a 'Labour Welfare Fund', and the best villagelevel governing bodies in each district will also be eligible for cash bonuses. All children of 'eligible' government employees will be entitled to reimbursements of medical expenses up to the age of 5 ; thereafter only two of them will be given this facility. Employees who already have more than two children will only receive medical reimbursements if they are sterilised within a year of the date of enforcement of these decisions.

The disincentives are aimed primarily at government employees with 